\title{
KEY ITEMS OF INNOVATION MANAGEMENT IN THE PRIMARY HEALTHCARE CENTRES CASE STUDY: FINLAND
}

\author{
Alireza Aslani1, ${ }^{1,}$, Mohammad Mahdi Zolfagharzadeh², Marja Naaranoja ${ }^{1}$ \\ IIndustrial Management Department, Faculty of Technology, University of Vaasa, Vaasa, Finland \\ ${ }^{2}$ Interdisciplinary Department, Faculty of New Sciences and Technology, University of Tehran, Tehran, Iran
}

\section{SUMMARY}

Trends such as aging populations, excess costs, rising public expectations, and progress in medical science and technologies point out the necessity of adaptation and development of innovation in the healthcare systems particularly in developed countries. The main objective of this article is to review diffusion of innovation in the healthcare sector. Different types of innovation, diffusion characteristics, and adoption mechanisms are the subjects that are discussed in the selected case study, Finland. Finally, the key items of innovation management in the Finnish health system are introduced. The results can be implemented in other countries as well.

Key words: diffusion of innovation, healthcare centres, adoption mechanism, Finland

Address for correspondence: A. Aslani, University of Tehran, Faculty of New Sciences and Technology, Interdisciplinary Department, North Karghar St., 1439957131 Tehran, Iran. E-mail: Alireza.aslani@ut.ac.ir

\section{INTRODUCTION}

Access to high quality health services is one of the main tasks of today governments. However, the level and quality of these services highly depend on the factors such as economic conditions, population, governmental budget, and age pyramid $(1,2)$. For instance, while ageing population increases health expenditures for government especially in developed countries, the economic crisis decrease the quality of the services. The researcher investigations show that reasons such as excess cost, long waiting periods, geographical distances, lack of knowledge and incentive affect health inequalities in developed countries (3). Indeed, concerns and trends such as ageing population, shortage of local healthcare manpower, advances in medical science, and increasing expectations along with budget limitations threat the healthcare systems in the developed countries (4). To overcome the challenges, policy makers have tried to use healthcare resources more effectively. Therefore, they have considered different strategies such as prevention and incentives strategies among population, technological development in the healthcare systems, diffusion of integrated IT systems, privatization of the healthcare systems, and increasing public awareness through social media (5). The diffusion and adoption of innovation, in the different frames, are also important policies for value creation to improve the health system on different levels such as national, regional, local, and in healthcare centres. Innovation is a driving force to speed value creation and balance cost containment with healthcare quality in health systems (2). However, despite enormous investments in the diffusion and adoption of innovation in the health system, outcomes are not effective and even in some cases fail (6). In most cases, the failures of innovation programmes occur because of the complexity of innovation in the healthcare sector.
Given the importance of innovation diffusion in the healthcare sector this comprehensive study focus on the adoption of innovation in the healthcare system. We have chosen Finland for the case study.

The research starts with overview of Finnish healthcare system. Then, factors affecting the system are discussed. After that, the effective characteristics of innovation in the health system are reviewed. Finally, based on a qualitative research the key items of the Finnish healthcare system are identified.

\section{Literature Reviews}

\section{Overview of Finnish Health System}

Compared with other EU countries, Finland, as a part of the Nordic model of the social welfare, has a broad scope of social policies and universal social benefits (7). Policies such as services free or subsidized health care delivery, a high proportion of GDP spent on social and health services, or equal gender and income distribution are examples of the Finnish social system (8). On the other hand, the Finnish health system is based on the public ownership of hospitals and decentralized responsibility for health services management. These features go along with equal access and low cost level of health services and high levels of tax based financing (9). The Finnish health system includes a mix of public and private resources. Public financing comes from the central government and/or local municipalities. They are primarily responsible for financing of health services. Public financing covers more than $75 \%$ of health expenditure in Finland. In addition to the public municipal system, private healthcare excluding occupational services accounts for $6 \%$ of total healthcare expenditure (10). 
The health system is more decentralized compared to other EU countries. In Finland, there are about 336 municipalities providing two thirds of public services. The municipalities are also responsible for managing both health and long-term care services (such as hospitals) (7). There are a few central regulations of the municipal health service, thus, the municipalities benefit from greater autonomy in terms of using income tax, health investments and organization of services (11). The decentralized hospital system is a part of purchaser/provider model in Finland. According to this model, municipalities have the role of purchasers and the hospitals of the providers.

The health care centres have an important role in the Finnish health system with a variety of services such as physiotherapy, child welfare, school healthcare, dental care, and psychologist service. Overall, the Finnish healthcare system is funded by taxes and benefits from the decentralized public governance structure, control/ownership of services by public sector, emphasis on geographical and social equity, and public participation.

\section{Factors Affecting Finnish Healthcare System}

Although the Finnish healthcare system has been developed during the past two decades, the health-economic indicators show that health indicators has recently dropped compared to other developed countries. For example, although the total health expenditures in Finland showed 25\% growth compared to 2006 (8.9\% of GDP), it was still $6.7 \%$ less than the OECD average (9.5\% of GDP for 35 countries) $(10,12)$. This indicator is also low in Finland compared to the Nordic average (9.85\% of GDP) (12). Figure 1 shows the challenges of the Finnish healthcare system.

Ageing people increase the demand for health care services and affect the types of demanded services. Ageing population also increases pressure on the costs. On the other hand, lifestyle changes that lead to higher incidence of cancer, diabetes and heart diseases are factors affecting the quality of health care services. The operational efficiency is one of the important issues of the current Finnish healthcare system. In order to respond to this challenge the primary health care centres and hospitals have restructured their facilities and equipment using advanced technologies. However, a shift towards high-cost technological equipment

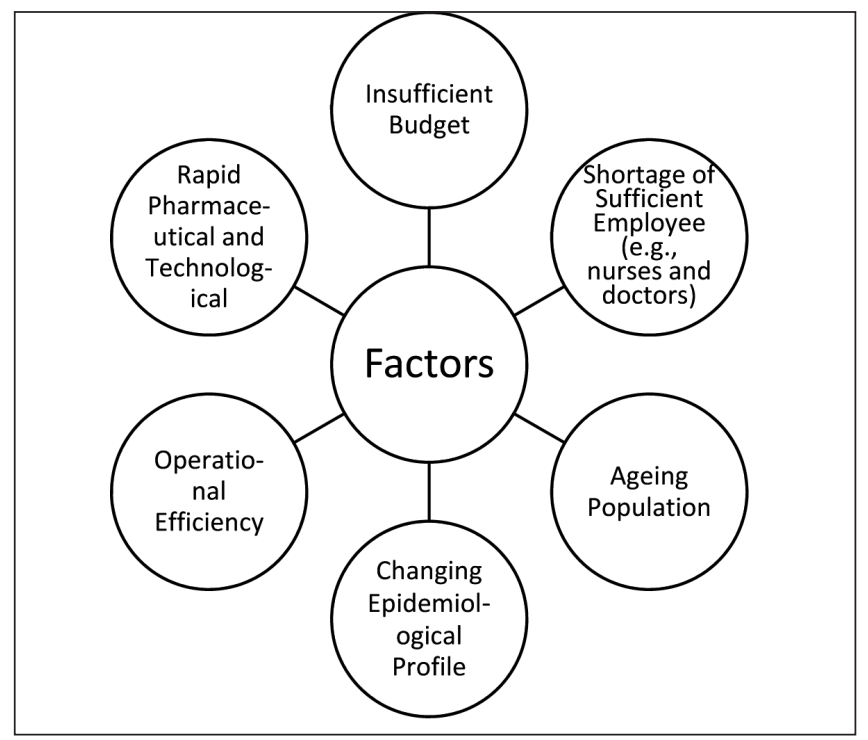

Fig. 1. Factors affecting the Finnish healthcare system. and the necessity of having young administrative employees and nurses to adopt new technologies have increased the costs of the Finnish healthcare system. On the other hand, concerns related to maintaining the quality of healthcare system, in particular of specialized services, have resulted in decisions to reconfigure the hospital sector into fewer and larger administrative units. This is also a reason for increased health sector budget.

Moreover, Finland has a low population density, especially in the north part. To maintain geographical equity of healthcare system increases the costs of the heath care deliveries. Since taxes are the main budget source, the high tax rate brings pressure on the government to allocate the lower budget to other public sectors such as education, culture, etc. The recent trends and policies, in particular after the economic crisis during 2011-2014, show these effects in Finland. Furthermore, while high tax rate affects the production and competitiveness of Finnish products or services, it also affects the social welfare.

\section{Effective Innovation of Health System}

Figure 2 illustrates the general framework of innovation process in the Finnish health system (12). The framework comprised three aspects of enablers, processes and outcomes. "Enablers" are the characters that effect the diffusion of innovation within or across work units and departments. In other words, innovation enablers include the efforts of nurses, doctors, managers, and policy-makers to implement creative and innovative ideas and methods into the healthcare system (process dimension). The "process" dimension of innovation refers to how the healthcare employees implement the enablers of innovation in their workrelated experience and expertise. Several studies have been conducted to analyze this dimension $(12,13)$. Finally, "outcomes" dimension reveals the effects of creativity and innovation management on the healthcare performance indicators. Bellow each character of the enablers is reviewed.

The success of creativity and innovation in an organization depends on individual characteristics. Our studies show that personnel attitudes to creativity and innovation, perception, motivation, personality, biographical factors, and job satisfaction are the main important factors affecting the level of creativity and innovation in the healthcare system $(12,14,15)$. According to the systematic characters, the factors related to the organization of the Finnish healthcare system and formal and informal groups are considered. The analysis of interviews indicates that the possible communication among the professionals, organizational culture, team working, supports from/of the supervisors or managers, learning and implementation of creativity and innovation techniques, and bureaucratic process (as a big barrier) are the most important factors affecting diffusion of innovation in the health systems (15). Specifically, an organizational climate that encourages new problem-solving method and creative ideas is one of the big identified gaps in the Finnish healthcare system. On the other hand, creativity and innovation techniques are tools that include selected heuristics for directed stimulation of thinking process. This indicates that the creativity techniques can be an important part of organizational processes especially in the Finnish healthcare system. Finally, structural characters discuss about issues that are more than behavioural aspects (12). For example, one of the main barriers of creative ideas in the Finnish healthcare system is the lack of time for nurses and doctors to 


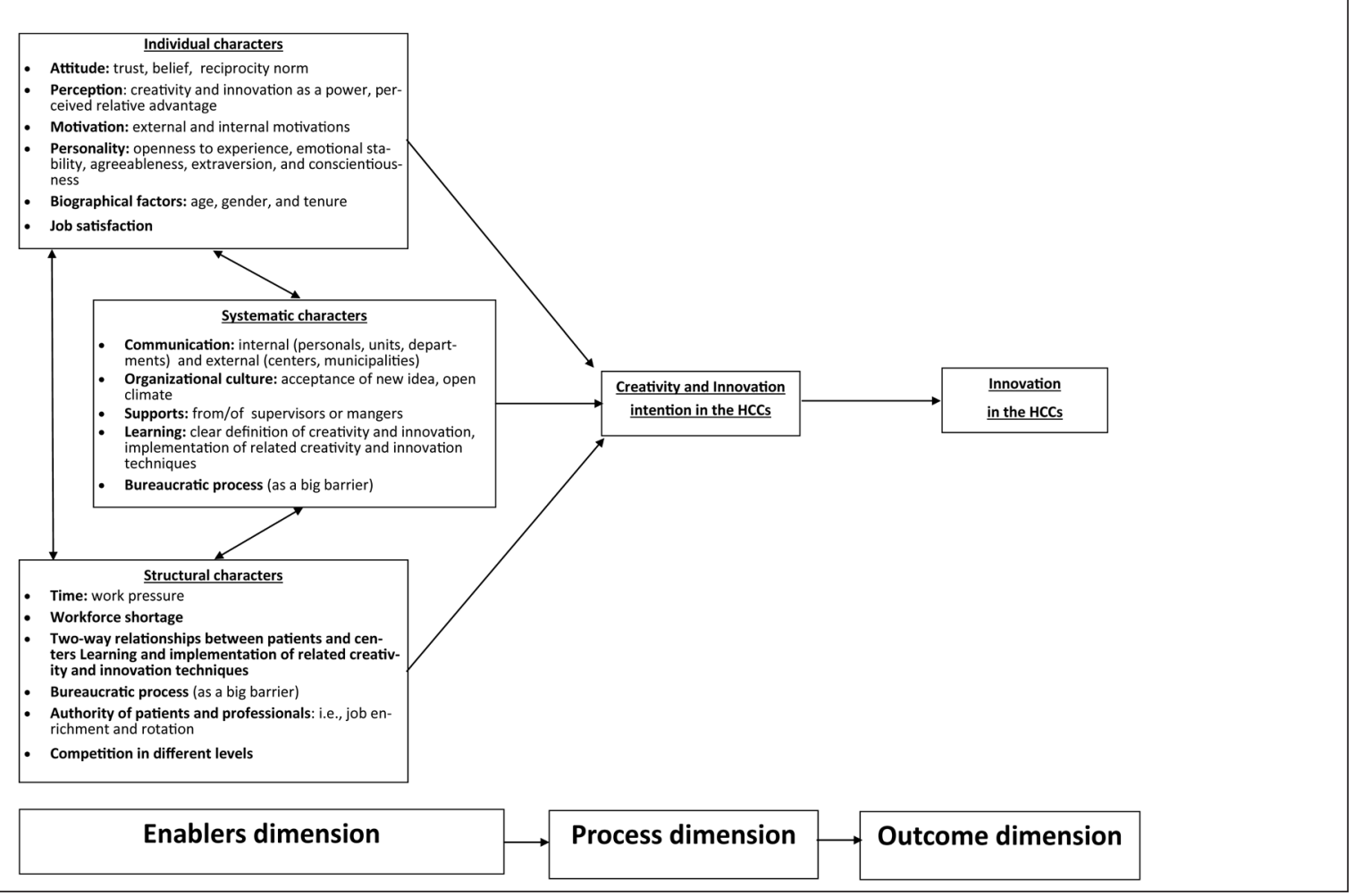

Fig. 2. Framework of the ideation and innovation processes in the Finnish HCCs.

think innovatively. The analysis of interviews shows that almost all of the respondents believe that the workforce shortage is the main barrier to think innovatively. As this caused work pressure, it harmed staff's motivation. In the previous studies of the authors, all characters and their causal relationships have been completely described and discussed $(12,16,17)$.

\section{Research Scope}

The diffusion and adoption of innovation in the service sectors such as health is often accompanied by difficulties. Studies show that the innovative reforms in the healthcare system could be assessed from two viewpoints: content and process. From the content point of view, the innovation in the healthcare system is assessed by determination and measurement of the innovation achievement indexes at a specific level such as regional, national and local (18). From the process point of view, the changes and effects on the strategies and policy objectives are assessed followed by institutional changes in order to be more innovative at levels such as primary health care and health education. Since different studies from content viewpoint have been conducted in Finland, this study assessed the innovation from the second point of view.

The research of the Finnish healthcare system was conducted during a period of twelve months and qualitative analysis was used. Figure 3 illustrates the qualitative framework of the data accumulation and analysis method. To organize and extract key items of innovation management in the Finnish health system and create the conceptual frameworks, NVIVO 9 (QSR) software was used. NVIVO is a tool for qualitative research using rich textbased and/or multimedia information. The software helped in data management, ideas managing and querying of data. According to the Figure, the collected data were numbered in the order of each category and related question, and then coded. About 40 hours interviews with doctors, nurses, professionals, and managers were recorded (questionnaires and audios). In addition, over 2,000 pages of documents and articles including annual reports, detailed government, project reports, and published investigations were categorized and reviewed.

In the next step, the mutual points of each code and memo were recognized and filtered. Finally, the key items were selected and introduced. Since the review and reprocessing was strictly performed in each stage, the research validity is ensured.

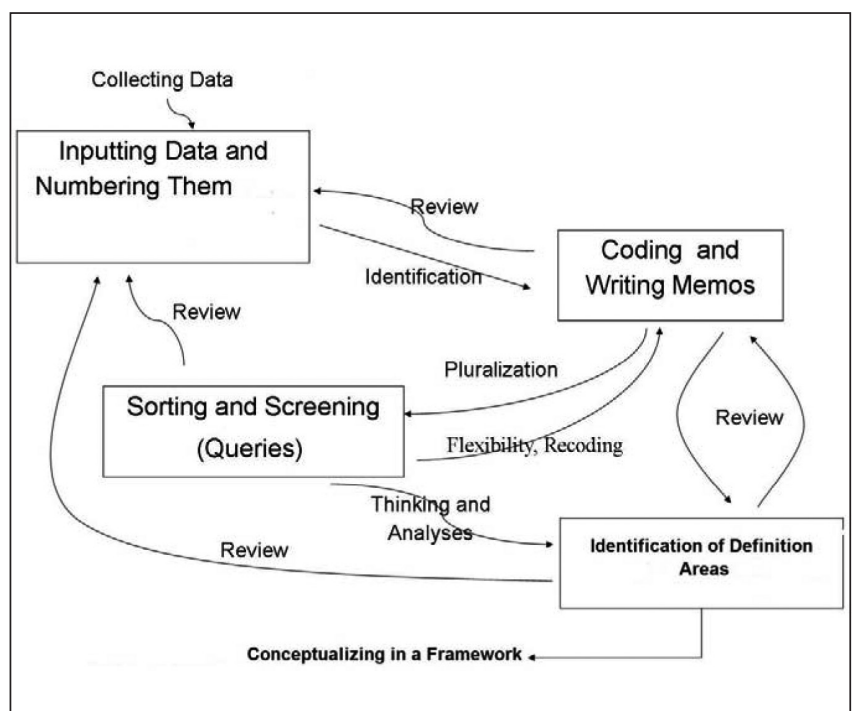

Fig. 3. Qualitative framework of the data accumulation and the analysis method. 


\section{Analysis}

Innovation in the health system is defined as introduction and implementation of a new idea, service, technology, and method of work, product to improve treatment, diagnosis, outreach, prevention, and education. It also improves the outcomes, quality, efficiency, costs of healthcare systems. As Figure 4 illustrates, different types of innovation are implemented in the health system $(16,19,20)$.

Organizational/administrative innovation introduces the implementation of a new organizational or structural method in the health system, workplace organization, or external relations with government, municipalities, healthcare sectors, networks, etc. Product/ technology innovation includes introduction or implementation of a good or technology that is new or significantly improved into the health system. It comprises significant improvements in technical issues, components and materials, incorporated software, or other functional characteristics $(19,21)$. The innovation process includes implementation of a new or significantly improved process of service (e.g. equipment and/or software) (22). Delivery innovation refers to the implementation of a new delivering or marketing method involving significant changes in service design or packaging, health service placement, and care costs (23).

The result of this study shows that organizational form within organizations is a key item of the Finnish healthcare value system. This means that the increasing productivity is an important factor and the system should lead to more efficient health services by organizing efficient forms of outsourcing, co-design, comanufacturing, and logistics.

On the other hand, field of publicity, marketing, sales, and institutions that stimulate economic transactions are some points that should be more considered in the Finnish healthcare system.

Furthermore, the lack of clear business model is another finding of the research. This means that the Finnish healthcare system needs new and original ways of composing a value chain and earning income.

Finally, the share of networking among different partners of the healthcare system is an important issue for the Finnish system. Figure 5 illustrates the identified sub-system of Finnish healthcare system at the municipality level that the networks between the nodes can introduce and improve in each relation.

The system places requests of supports including financing and/or professional-technological requirements to government or municipality and receives requested services. The policies and

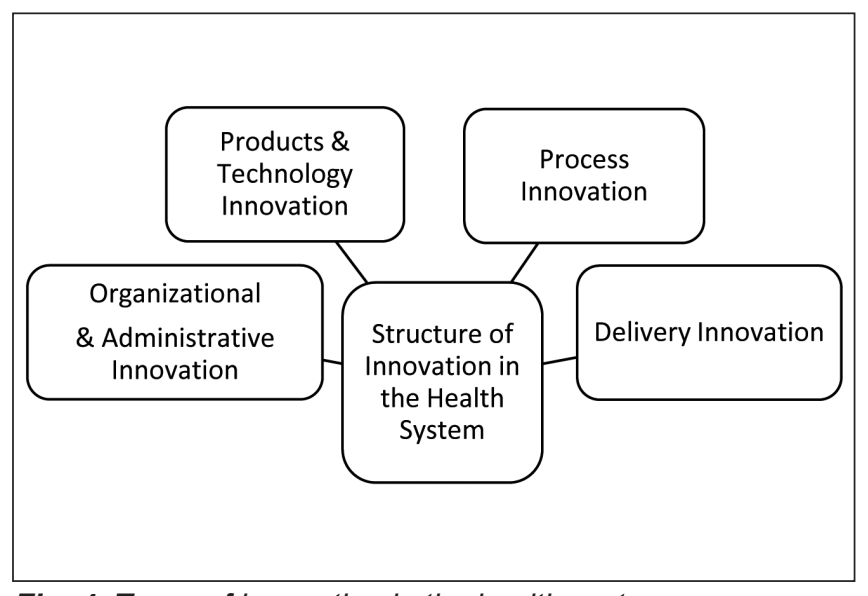

Fig. 4. Types of innovation in the health system.

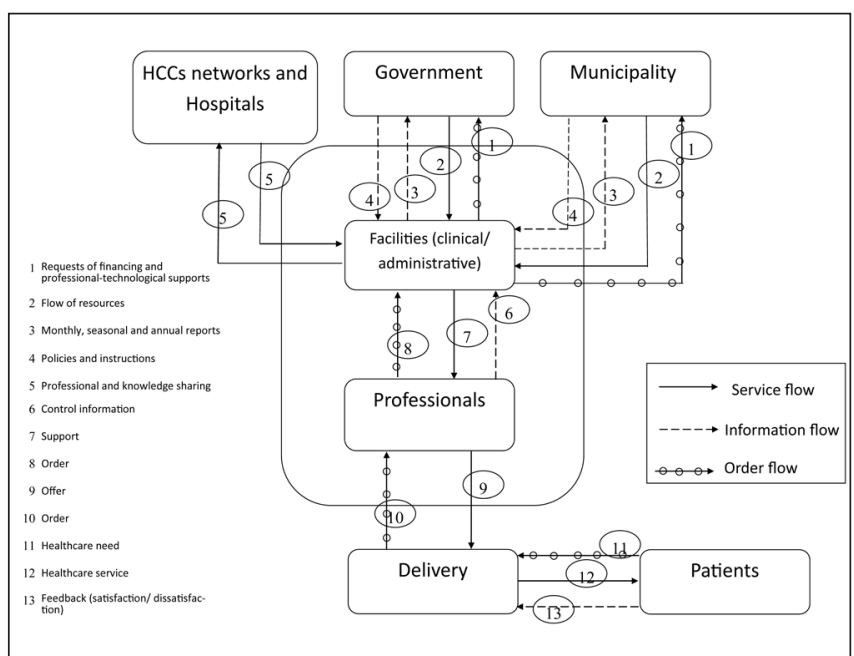

Fig. 5. Subsystem diagram for the Finnish healthcare system at the municipality level and network nodes.

decisions also come from the government and municipality in the frame of information flow. In response, different reports are sent back by the system. Further, the Finnish healthcare system interacts with other networks for knowledge sharing, trainings etc. The system is depicted as two interacting subsystems, facilities (clinical/administrative), and staffs and professionals. The facilities (clinical/administrative) subsystem covers issues such as system management, policies, and instructions. It is the hearth of Finnish healthcare system with an important role of innovation performance in the system. The staff and professionals subsystem also contains policies for manpower and hiring. The major information, orders and service connections between this subsystem and facilities and delivery subsystem are shown in Fig. 5. Each flow and related subsystems have potential nodes for implementation and adoption of innovation. As care delivery is an important part of innovation studies on healthcare sector, it shows a subsystem between the interactions of patients and Finnish healthcare system.

\section{CONCLUSION}

Although healthcare systems have experienced different kinds of administrative or clinical innovations, assessments show that the impacts of innovations in reality have not met expectations particularly in primary healthcare centers. This paper discussed the important issues of diffusion of innovation among the staff and professionals of the primary healthcare centres and reviewed the adoption mechanism. We categorized and discussed the diffusion process of innovation in the Finnish healthcare system from different aspects. As the main result we identified the importance of defining a clear business model and networking. The future studies should address the effectiveness of key items. The effects on health system stakeholders as well as role of government are other issues that should be reviewed in the future studies.

\section{REFERENCES}

1. Gray M. Value: Operations Research and the new health care paradigm. Oper Res Health Care. 2012 Mar;1(1):20-1. 
2. European Commission, Economic Policy Committee. Joint report on health systems. Occasional Papers 74. Brussels: European Commission; 2010.

3. Aslani A, Naaranoja N. Characters of innovation management in the primary health care centers. Organizacija. 2013 May;46(3):108-14.

4. Aslani A, Naaranoja N. Mechanisms of innovation improvement in the primary healthcare centers. IJPPHME. 2013;3(2):35-45.

5. Winblad I, Viramo P, Remes A, Manninen M, Jokelainen J. Prevalence of dementia - a rising challenge among ageing populations. Eur Geriatr Med. 2010 Dec;1(6):330-3.

6. Teperi J, Porter ME, Vuorenkoski L, Baron JF. The Finnish health care system: a value-based perspective. Helsinki: Sitra; 2009.

7. Rantanen J, Kauppinen T, Toikkanen J, Kurppa K, Lehtinen S, Leino T, Work and health country profiles: country profiles and national surveillance indicators in occupational health and safety. Helsinki: Finnish Institute of Occupational Health; 2001.

8. Magnussen J, Vrangbæk K, Saltman RB. Nordic health care systems recent reforms and current policy challenges. Maidenhead: McGraw-Hill; 2009.

9. Lundberg U. The Nordic model: past glory or the way of the future? Stockholm: Institute for Future Studies; 2006.

10. Health at a glance 2011: OECD indicators. Paris: OECD Publishing; 2011.

11. Häkkinen U. The impact of changes in Finland's health care system. Health Econ. 2005 Sep;14 Suppl 1:S101-18.

12. Aslani A, Naaranoja M, Diffusion of ideation and innovation in the Finnish primary health care centers: an action research. In: 2012 IEEE Healthcare Innovation Conference: Translational Engineering in Health and Medicine; 7-9 Nov 2012; Houston, TX.

13. Fleuren M, Wiefferink K, Paulussen T. Determinants of innovation within health care organizations: literature review and Delphi study. Int J Qual Health Care. 2004 Apr;16(2):107-23.
14. Aslani F, Mousakhani M, Aslani A. Knowledge sharing: a survey, assessment and directions for future research: individual behavior perspective. World Acad Sci Eng Technol. 2012;6(68):310-4.

15. Aslani A, Naaranoja M, Kekale T. Application of creativity techniques in the creation of organizational strategies. Int J Eng Bus Manag. 2012 Aug 8;4:14.

16. Aslani A, Naaranoja M. A systematic-qualitative analysis of diffusion and adoption of innovation in the Finnish primary healthcare centers. Am J Public Health. Forthcoming 2012.

17. Aslani A, Helo P, Naaranoja M. Development of creativity in concurrent engineering teams. Am J Ind Bus Manag. 2012 Jul;2(3):77-84.

18. Rye CB, Kimberly JR, The adoption of innovations by provider organizations in health care. Med Care Res Rev. 2007 Jun;64(3):235-78.

19. Omachonu VK, Einspruch NG. Innovation in healthcare delivery systems: a conceptual framework. Innov J. 2010;15(1): 2.

20. Varkey P, Athyal VP. Service delivery innovations at Mayo Clinic. Minn Med. 2005 Dec;88(12):39-42.

21. Ogilvie DT. Creative action as a dynamic strategy: using imagination to improve strategic solutions in unstable environments. J Bus Res. 1998 Jan;41(1):49-56.

22. Clegg B. Creativity and innovation for managers. Oxford: Butterworth Heinemann; 2001.

23. Kekale T, Aslani A. Identification and ranking of related creativity and innovation techniques with creation of collective strategy by using MADM models based on fuzzy approach. In: Proceedings of 8th International Conference of Management; 2011.

Received March 7, 2013

Accepted in revised form July 31, 2015 